\title{
INTEGRATING THE EFFORTS OF OFF-SITE PRODUCTION WITH ON-SITE CONSTRUCTION
}

\author{
Roine Leiringer \\ Department of Construction Management and Economics \\ Royal Institute of Technology, SE-100 44 Stockholm, Sweden \\ Email: roine@recm.kth.se
}

\begin{abstract}
A study for the Swedish government on a 'design and build' project has examined the underlying process and has found a series of inconsistencies between what is claimed and what appears to have happened. The project could not regarded as having been especially complex. Even so, detailed analysis using computer modelling techniques has shown it to be other than a trivial affair. The investigation is documented as a set of computer-based process models, which has been used to pinpoint failures in communication and information management. The findings show that the present understanding of project workflow is not sufficient and that not enough effort is put into this issue in the early stages of project planning. This is particularly significant in the synchronisation of off-site production with on-site construction. Conclusions have been drawn that support the argument of a more detailed analysis of the process. The use of process models to establish clearly the workflow for all involved actors would improve present project planning and scheduling performance. By so doing, projects would become more clearly defined and straightforward, thereby increasing the likelihood of a successful completion.
\end{abstract}

Keywords. Project planning, computer-based modelling, off-site production, workflow.

\section{INTRODUCTION}

Improvement in the construction sector is a topic of current debate. Construction companies and consultants are looking at ways of raising quality, lowering costs and shortening project times. Research is being conducted on all levels within the projects not least including attempts of automating the construction process by applying new technology to traditional building methods. This strive for improvement is not going unnoticed by the clients of the sector who see the potential benefits too. Expectations have risen and new ways of working are being promoted to emphasise teamwork and greater involvement of the client organisation. The nature of construction however makes it anything but a trivial affair. The number of actors involved, activities being undertaken and decisions to be taken contrive to make the process less than certain. Even the most basic of actions could very well fail unless the right information is communicated to those that need it, when they need it and in the form that they need it. Too much is often taken for granted and failure to deliver what has been expected is not uncommon even amongst the simple straightforward projects. The construction industry seems yet to have fully recognised the importance of correct management of information and the large scope for improvement that should be possible in this area. It has been claimed that actors on all levels in the projects tend to spend as much as $30 \%$ of their time exchanging information with other parties (Olsson et al., 1999). One proposed solution - and the one covered in this paper - is the use of detailed process models to assist in managing construction projects. These models can show the entire process for the project down to a fairly detailed level, providing a hierarchical and integrated view of the project. The result is a common ground for the client and all involved actors on which to base their work. Views to the contrary, that this is not achievable, are common, not least among practitioners. It is claimed that the process is far too complex to be modelled and that even if it were possible it would be of no use as every project is unique. However, research has shown that there are great similarities between the projects, even across different countries (Atkin 1998) and detailed modelling of the process in different forms has already been conducted with many useful insights being gained (Kagioglou et al. 1998, Karhu et al. 1997). 


\section{BACKGROUND}

In 1996, the Swedish government initiated an investigation within the Ministry for Industry, Employment and Education. The aim of the investigation was to create long-term reductions in the costs for construction and maintenance of social housing, thereby lowering the cost of housing and raising employment in the construction sector. A special committee of enquiry - Byggkostnads delegationen (BKD) was created to undertake the work.

This paper is based on the findings from a case study conducted on one of the test projects initiated by BKD. The project in question consisted of the construction of three adjoining buildings with a total of 44 flats specially suited for elderly living. The work was undertaken as 'design and build' with the construction phase running over nine months. The main actors were a regular client of the sector and a 'design and build' company.

The project was initiated under the assumption that benefits would accrue from an open and transparent sharing of information between the actors and an increased use of pre-fabricated products. The main objective of the case study was to measure and evaluate how an increased collaboration between client-contractor-suppliers could influence the quality of the end product and the costs of production and maintenance.

\section{METHODOLOGY}

The method adopted for the research was based principally on a detailed analysis of the processes supporting the housing project. A single model of the project was created using computer software based upon functional modelling techniques. These were used to document activities, their relationships and associated inputs, controls, outputs and mechanisms (Feldmann, 1998). The computer software product, BPwin, was used. It is based on the US IDEF0 Federal Information Processing Standard for function modelling.

Interviews with key project personnel were conducted in order to obtain a complete (or as near a complete) picture of the activities that were undertaken, the information flows that these needed and generated, and the resources that were necessary for their completion. It was assumed that the information flows and activities reported in these interviews had taken place in the manner described. To validate and refine the model repeated visits were made to the site. These visits were observational and did not impede the work. Discrepancies from what was said in the interviews were picked up and errors and defects were noted. Furthermore, a review of the documentation produced during the course of the project, originating from both the client and the project team, was undertaken.

The model was compiled from a functional decomposition of the project as a whole. Views of parts of the model were generated and used to 'walkthrough' representatives from both client and contractor organisations. Where necessary, sections of the model were altered or adjusted and 'walked through' again to achieve as near a replica of real life as possible. The resulting model covered in excess of 80 A4 pages and took the form of an integrated set of hierarchical diagrams. From these it was possible to probe the detailed workings of the project and to identify areas in which further study was needed.

\section{MAIN FINDINGS}

The housing project studied is for Swedish standards, reasonably large but with the exception of that certain considerations had to be made in the design stage to adjust the product to the specific requirements of elderly living. That aside there was nothing in particular that separated it from any mainstream construction project. The project was considered as a success overall and the main actors have agreed to continue their relationship in coming projects. However, a detailed analysis of the workings shows that large parts of the process were not adequately defined and assigned and that many of the time, cost and quality errors that occurred could have been avoided or kept to a minimum. In other words, further improvement could be achieved. Phases in the process where this was especially apparent were the project initiation and definition stages and the general management of the supply chain.

\subsection{Project initiation and definition}

Construction deviates from most other industries in the way that the projects are initiated, which makes the early stages of the project i.e. the initiation and definition stages probably the most crucial of all for making the project successful.

\subsection{Briefing}

Briefing is probably the most decisive of phases in the procurement process. The basis of the brief will normally be determined by requirements stated as objectives and priorities. These objectives generally take the form of statements as to the cost, time-scale and some aspects of quality. The funds available will be fixed, as might the time for completion of the building. However, the actual need might be quite difficult to ascertain as the client's business plan may embody stipulated corporate, financial and other requirements and 
may not, therefore, have been drafted in a way that enables the project team to use it directly. Interpreting these requirements is an important exercise that has to be done in a structured and methodical manner. It is the objectives in the brief that set the main working parameters for the project and challenges the team to produce the required quality. Unrealistic objectives for time, cost and quality and, equally, impractical trade-offs between them will inevitably result in a less than satisfactory outcome. Priorities should be stated in terms of which objective is of the greatest importance and how the others relate to it.

Some of the performance failures on the case study project could be traced back to the inadequate definition of needs and the relative ordering of priorities. One cause was that the project objectives and priorities were not recognised and shared by all members of the project team. The parties came into the project carrying with them their specific ideas and standard procedures for how the work is supposed to be conducted. Insufficient knowledge and understanding of how the other involved parties conduct their business and not sharing the same view on how the project was to proceed and exactly what that was required of each of the activities in the earliest of stages meant that the parties were illprepared and could not exchange sufficient information with each other. Meetings were, on repeated occasions, forced to be held over again, effectively slowing down the process. Certain issues that were disputed by the parties during the project came as a direct consequence of misinterpretations in these early stages. These misunderstandings ranged from technical aspects, such as the type of taps and plumbing arrangements in the pre-fabricated bathroom modules, to the finish of the facade.

\subsection{The project team}

Project success derives largely from the actions and interventions of those that are conducting the work, i.e. the various members of the project team and those associated with them. None of the workings of the process should be the private affair of any member of the project team. Awareness of what each team member does is of paramount importance if communications and actions are to be effective. The participating organisations in a construction project are often involved in several other projects simultaneously. Total commitment of team members over the entire duration of a project could, therefore, as became the situation on the case study project, be difficult to achieve. In the study, the 'design and build' company had difficulties in convincing a few suppliers to adopt the principles on which it based its work, one example being the application of Just-In-Time thinking. There are, however, some simple steps that the client can take to ensure that the team remains focused on the project objectives and priorities. An explicit project plan, such as was developed on this project by the author would help each organisation and person to establish the required mode of working. Team members can then be expected to act promptly and correctly. A plan would also ensure that members are fully conversant with their roles and responsibilities and, equally important, that others are aware of them too. The project plan must define the process - from initiation to occupancy - in such a way that the client can see what is to happen on the project and thereby be able to impose constraints as to make as good as possible interface with his own business plan. Moreover, the project plan must show clearly and unambiguously the actions, their sequence and times that are needed to complete the project (Atkin, 1999). A detailed project plan would enable the full sequence of decision-making to be taken into account from the start of the project. This means a more certain process where risks could be properly identified and assessed and passed to the party that can best manage them. Bringing transparency to decisionmaking and, at the same time, throwing light on the actions required of each team member enables the project team to concentrate upon doing the job to the best of its ability. The use of a plan could also pave the way to a process of continuous improvement by defining a baseline from which to measure subsequent performance. Reducing costs by eliminating inefficiency and waste comes about from a thorough understanding of how the present work is performed. In the case study project it transpired that there were actors who had not recognised the full extent of the work that lay ahead of them. The effect was that they could not fulfil their commitments and the knock-on effects from their default effectively impeded the performance of several other actors - even the smallest of team members have an important role to play to make the project successful.

\subsection{Programme and time management}

Correct and timely decisions are crucial for the success of a project and it is the timing of key decisions that is likely to determine the pace of the project more than anything else. During the course of the project it became obvious that the bar charts and other graphical representations that show when decisions have to be taken not always enabled a proper understanding of what must be done to enable the decisions to take place. It is therefore necessary to expand the role of project planning (i.e. method and time management) to incorporate decision-making. Bringing transparency into decision making creates a more secure environment for the involved actors to plan and perform their work. The project plan is intended to show where in 
the process decisions have to be taken, who will be involved and the information required. The implications of a change of schedule, or design, can only be considered properly if there exists an understanding of the underlying processes and the flows of information and actions needed to maintain integrity of the project plan based on a comprehensive model of the entire process. Bar charts and precedence diagrams should be used in conjunction with the project plan.

Practical steps to reducing or eliminating risks starts with a process which is visible to everybody and about which there can be few misunderstandings. The use of a project plan, which is shared by everyone, will help to identify areas of risk as well as keeping track of which actions are required when and by whom. It can be extremely helpful early in the project's life by acting as a checklist. Overall, a project plan is likely to ensure that fewer risk items are overlooked.

\subsection{Coordinating the specialists}

Construction is by nature a fast-moving and dynamic work environment with most of today's building projects requiring the service of several specialists. This was also the case in the case study project there the specialists were needed not just for constructing or assembling elements or components of the building, but also for undertaking parts of the design. Managing the interfaces between various specialists requires close attention. This includes all aspects of the design as well as work on site and the integration of both. Several failures in the performance of the buildings in the project resulted from mistakes made at the interfaces between components and/or the organisations responsible for them. Two typical examples being insufficient assembly instructions and product information delivered by the supplier of the pre-fabricated modules to those in charge of the assembly and the lack of communication from the supplier of the floor components. Both of these independently caused delays as it turned out to be impossible to keep within the required tolerances. Coordinating the work of specialists is a necessary task and one that has to be resourced adequately. Ensuring that the scope of work covered by respective specialists is complete is key to efficient development of the design - there should be no gaps - communication and exchange of information is essential. There has to be an established organisational infrastructure that maintains a competitive element between the parties at the same time as the actors have open access to each other's processes. This means sharing information about how decisions are arrived at and assumptions that are made along the way as well as providing insight into present progress of work.
Visits to the design offices and works of specialists are highly recommended even though the specialist may only be responsible for a small part of the project. One such visit was made in the case study project. Representatives from both the client and the 'design and build' company visited the manufacturer of prefabricated modules. Even though it was meant as an information gathering visit, important weaknesses concerning both structural and functional aspects of the product were discovered and passed to the manufacturer. The findings show that telephone calls and verbal assurances are not sufficient substitutes for a physical presence to check the facts. Subsequent visits, once the project is underway, ensure that there is no deviation from what has been agreed. Surprises generally result from a lack of return visits. Moreover, simple calculations show that the cost of the additional supervisory and management resources will be amply repaid.

\subsection{Logistics}

Even some fairly straightforward construction activity on the project went beyond the requirements of many industrial sectors in demanding the close coupling (or scheduling) of these key resources (or factors of production). Assuring the timely delivery of supplies and the arrival of specialists is an obvious factor in the success of any enterprise where materials, labour and machinery have to be coordinated. When one talks of waste on a construction site, this extends to all three factors - materials, manpower and machinery. Greater effort can, as it was in the project, be put into the control of on-site activities to minimise waste. However, the same cannot be said of the 'hidden' off-site activities since they were generally viewed as being someone else's problem. Using the work-site telephone to make last minute alterations in quantities and timings of deliveries might be necessary in certain situations but it is not the most efficient way of managing the supply chain. Much more has to be done in the early stages of the project - synchronising the arrival of the right components, at the right time, with the right availability of labour and machinery will reduce wasteful working and lead to lower costs for the client (Atkin and Leiringer, 2000). The way to ensure the correct synchronisation of deliveries with the demands on site is to leave little or nothing to chance and regard this aspect of project management as deserving of appropriate supervision and resources. Construction companies need to ensure that not only is the delivery timely, but that the content is in accordance with the on-site production schedule. Delivery errors that occurred in the project included the quantity of components supplied, their conformance with the specification and their arriving in the wrong sequence. It 
happened that the suppliers delivered components to site in a sequence or batch that suited their own production, but which was at odds with the requirements of the construction site. Control of delivered goods was conducted by the assemblers who were only required to check the amount of components as they were not considered to have sufficient competence to control the quality. Having trained staff to undertake this task turned out to be a difficult concept to sell to the actors involved, despite the obvious imbalance between the cost of consequential delays and errors and the part-time employment of a 'chaser' or 'expediter'. For the relationship to work and for the supply chain to function efficiently requires an organisational infrastructure that has checks built into it. Checks that, unlike those conducted in the case study project, must be based on more than spoken assurances by suppliers and assumptions made by the 'design and build' company that the work will be done properly. To say that failure of a trusted supplier will result in its not being considered for the next project is no comfort to a client who has a late and expensive building.

The pursuit of zero delivery errors is only meaningful if there is action to follow this through. This requires that reasons be identified for the cause of the error. Simple causal analysis could be enough to ensure this happens, so long as the findings are recorded and acted upon to avoid repetition. Once this practice has become routine as in fact it must if one is working to a quality system - it is likely that many of the common, easily avoidable problems will disappear. One must, unlike in the case study project, avoid relying on individuals' memories and, instead, hard-wire error avoidance into organisational procedures.

\subsection{Quality failures}

Quality can be defined in many ways and is probably the most difficult of the project's objectives and priorities to define and to obtain agreement upon. Independent of how well the requirements are stipulated, it should be in every actors interest to provide as good a service as is possible. This seems to be likelier if all actors are working with a shared understanding towards a common goal. Tracking the cause of quality failures, which is already routine in many industrial sectors, should be a routine part of every project. In construction this work is not always conducted in a satisfactory way. Elsewhere research has been conducted to quantify this problem in the railway sector, and has revealed failure costs in the region of $10 \%$ of the production costs (Nylén, 1999). Even though no quality-control regime is capable of turning a bad job into a good one, knowing the real cause of a defect can lead directly to improvement in the product, process or both. In the case study project the plain truth was that all quality failures were not sufficiently quantified and analysed. More could and should have been done. It is obvious that going back and putting work right costs more than getting it right first time. The entire exercise would have paid for itself. Tracking back to the cause of the failure (or defect) is a part of any quality system.

\section{CONCLUSIONS}

The research discussed in this paper is based on the detailed analysis of a housing project in which the actors have gone beyond their established procedures to create an open, transparent and, above all, collaborative atmosphere. The findings show that even though the project was judged as successful it turned out to conceal plenty of unnecessary procedures and wasteful working that clearly could have been handled in a far more effective manner. Construction is by no means a trivial affair - a more effective construction process comes out of all parties being fully conversant with their roles and responsibilities, knowing what to expect and what to do. Improvement could be reached by the application of clear guidelines, i.e. a project plan. The use of process models, amongst other improvements, could help all actors to identify the connections between the information, resources and components that are needed, both on and off the site, in a way that is not possible with project planning tools and bar-charts alone. Having a model that clearly shows the linkages between the activities, resources, information required and interrelationships would improve understanding as to what a change in or a deviation from the programme would have as a consequence on the project as a whole.

Whilst not intended to replace the project programme, a model of the kind discussed could be used to improve project programming practice. This would enhance the possibilities of successful implementation of new technology to traditional building methods.

\section{Acknowledgements}

The author acknowledges the contributions and supervision of Professor Brian Atkin, Construction Management and Economics, Royal Institute of Technology.

\section{REFERENCES}

Atkin, B (1998). Unravelling the value chain in construction. Proceedings Sixth Annual Conference of the International Group for Lean 
Construction (IGLC-6), Guaruja, Brazil, August 13-15, (available at http://www.ce.berkeley.edu/ tommelein/IGLC6/index.html) [2000-04-13].

Atkin, B (1999). Refocusing Project Delivery Systems on Adding Value. Lacasse, M.A. and Vanier, D.J. (eds) (1999). Durability of Building Materials and Components 8: Service Life and Asset Management, Volume Four Information Technology in Construction: CIB W78 Workshop. NRC Research Press, Ottawa, Canada.

Atkin, B. and Leiringer R (2000). Achieving Project Success in Building: A Best Practice Guide. Unpublished report, Royal Institute of Technology, Stockholm.

Feldmann, C.G. (1998). The Practical Guide to Business Process Reengineering Using IDEF0, Dorset House Publishing, New York.

Kagioglou, M., Cooper, R., Aouad, G., Hinks, J., Sexton, M. and Sheath, D. (1998). Final Report: Generic Design and Construction Process Protocol, The University of Salford, Salford.

Karhu, V., Keitilä, M. and Lahdenperä, P. (1997). Construction Process Model; generic presentstate systematisation by IDEF0, Technical Research Centre of Finland, Tampere.

Nylén, K-O (1999). Civil Works - Unique projects or a repeatable process?, Doctoral thesis, Royal Institute of Technology, Stockholm.

Olsson, R., Olsson, U.K-G. and Borgbrant, J (1999). Information management, partnering and performance contracts. CPR Convenor. Proceedings of the Second International Conference on Construction Process Reengineering (CPR-99). Building Research Centre, Faculty of the Built Environment, University of New South Wales, Sydney, Australia. 